Reprod. Nutr. Dévelop., 1981, 21 (6B), 1067-1075.

\title{
Selection for sperm quality in White Plymouth Rocks
}

by U. HAYE, A. van VOORST, R. PIT

Spelderholf Institute for Poultry Research,

7361 DA Beekbergen, the Netherlands.

Summary. A selection for sperm quality was carried out in the White Plymouth Rock population of the Spelderholt institute. The percentage of morphologically abnormal spermatozoa was used as the most important selection criterion. The population was selected in two directions, viz. a line with a low incidence (LI-line) of abnormal spermatozoa and a line with a high incidence (HI-line). Cocks were examined and selected at the age of 26 weeks with the help of vital stained sperm smears. The selection response in the LI-line appeared to be very evident; in the HI-line the results were more variable. An indirect effect of selection on 8-week bodyweight could be established.

\section{Introduction.}

At the Spelderholt Institute for Poultry Research artificial insemination is generally used for breeding purposes. All breeding cocks are examined to determine their sperm characteristics. There appeared to exist a relationship between the percentage of morphologically abnormal spermatozoa in the ejaculate and the fertility of the individual males. Cocks with less than 10 p. 100 of abnormal spermatozoa generally had a fertility rate between 90-100 p. 100. Inseminations were carried out weekly. The use of ejaculates with a higher percentage of abnormal spermatozoa increased the possibility of lower fertility. A considerable number of cocks with a high percentage of abnormal sperm cells appeared to be closely related to each other, and the same was true for cocks with few abnormal sperm cells in their ejaculates.

These facts gave rise to the initiation of a selection experiment on the incidence of morphologically abnormal sperm cells.

\section{Materials and methods.}

The experiment started in 1972 and the control population of the Institute's White Plymouth Rocks was used as a base population. Each generation was reared on the floor using a light period of 14 hrs.

At 18 weeks of age cocks and pullets were transferred to individual cages. The cages of the males were equipped with slatted floor in order to prevent foot sores and bruises. Feeding was ad libitum and a normal breeder food was used. No feed restric- 
tion was practised during the rearing period. Collection of sperm started at the age of 26 weeks after a training period of about two weeks. Collections were made twice a week. Special care was taken to avoid contamination with faeces, urates or transparent fluid. Determination of the volume of the ejaculate and preparation of semen smears took place immediately after the collection of each ejaculate, i.e. within two minutes. A mixture of cottonblue (aniline wasserblau) and eosin $\left(\mathrm{pH} \mathrm{7.2,696.6} \mathrm{mOsm/kg} \mathrm{H}_{2} \mathrm{O}\right.$ ) was used for vital staining.

A droplet of undiluted fresh semen placed on a slide and covered with a cover slip was examined with the aid of a phase contrast microscope to estimate motility. Concentration was determined using a colorimetric procedure. After the examination of all cocks from the control population, five individuals with a low incidence of abnormal spermatozoa, not closely related to each other, were selected as well as five cocks with a high incidence. Three pairs of full or half-sib sisters were chosen from each selected cock. One cock from each pair was used to found the LI-line; the other cock was used to found the HI-line.

The birds-were divided at random between the sires of each line, avoiding full-sib mating. Each sire was mated with six hens. During the breeding period artificial mating was carried out weekly using $0.10 \mathrm{ml}$ of fresh undiluted semen. As the minimum sperm cell concentration of the selected cocks was $2 \times 10^{9}$ sperm cells $/ \mathrm{ml}$, at least $200 \times 10^{6}$ sperm cells were inseminated.

As a rule each breeding generation consisted of two hatches. Hatching eggs were collected, stored, disinfected and incubated following standard Institute procedures. The eggs were candled seven days after setting and at day 18. True fertility was determined on the basis of an examination of the broken out clear eggs. Hatching results, recorded as the number of chicks obtained after 21 days of incubation, were expressed as the percentage of all eggs set (H/T.E.) and as the percentage of fertile eggs (H/F.E.).

The chicks were reared together under the conditions already mentioned. At the age of 26 weeks, two sons of every dam were trained and examined for sperm quality.

For registration of the results the following classification was used :

0-10 p. 100 morph. abn. spermatozoa : good ; 11-29 p. 100 morph. abn. spermatozoa : dubious ; 30 p. 100 or more morph. abn. spermatozoa : poor.

The following criteria were used in selecting the next generation :

- volume of the ejaculate : $0.3 \mathrm{ml}$,

- concentration : $2 \times 10^{9}$ spermatozoa $/ \mathrm{ml}$,

- p. 100 abnormal spermatozoa Ll-line : less than 10 p. 100 ,

- p. 100 abnormal spermatozoa Hl-line : more than 10 p. 100.

From each sire of the LI-line, the son (also meeting the other requirements) with the lowest incidence of abnormal spermatozoa was selected. From each sire of the HI-line, a son was chosen which had 15 to 20 p. 100 abnormal spermatozoa in its ejaculate while also meeting the other requirements. At the beginning of the experiment, cocks with a high percentage were disregarded because of the obvious danger of not obtaining enough offspring. Breeding hens were selected in both lines by choosing six full or half-sib sisters of the selected cocks. The hens were distributed at random among the selected males of the line, avoiding full-sib matings. The selected sires were reexamined before the actual reproductive period and once again shortly after the last 
insemination of the breeding period. The control population was maintained by choosing one son and one daughter of each family. They were randomized for breeding, avoiding the mating of full sibs. The breeding of this line had to be discontinued in 1975, however, on account of the reorganization of the Institute's breeding program. In 1976 the breeding system of the two lines was slightly changed to obtain more selection pressure in the HI-line. Two full or half-sib sons per family were selected; they were mated with three hens chosen and distributed as explained above, thus eliminating the risk of considerably reducing this line.

Males with about 30 p. 100 of abnormal spermatozoa were used in combination with a full or half-brother which had approximately 20 p. 100 of abnormal sperm cells.

\section{Results.}

The results of the selection experiments are summarized in tables 1 and 2 . Mean values of the sperm characteristics of all males, examined per line, are presented. The volume of the ejaculates decreased during the selection. Although the collection technique was not changed, there was probably some influence of increasing ability on the part of the assistant. A thorough analysis of this reduction remains rather speculative.

The mean percentage of normal sperm cells refers to the morphologically normal and unstained spermatozoa which are considered alive. The mean percentage of abnormal sperm cells refers to morphologically abnormal spermatozoa unstained and stained, i.e. live and dead. One of the matings in the F1 of the LI-line failed completely. Eliminating it seemed to be the only reasonable solution, considering the small base population, since its influence would have been disproportional. The offspring of one of the other combinations were split up and used for further selection.

The results of the control until the year of its discontinuation are presented in table 3 .

TABLE 1

Mean sperm characteristics of $L 1$-males ; means per generation

\begin{tabular}{|c|c|c|c|c|c|c|c|}
\hline \multirow{2}{*}{ Year } & \multirow{2}{*}{$n$} & \multirow{2}{*}{$\begin{array}{c}\text { Mean vol. } \\
\mathrm{ml}\end{array}$} & \multirow{2}{*}{$\begin{array}{c}\text { Mean conc. } \\
\times 10^{9} / \mathrm{ml}\end{array}$} & \multicolumn{2}{|c|}{ p. 100 norm. spermatozod } & \multicolumn{2}{|c|}{ p. 100 abn. spermatozoa } \\
\hline & & & & mean & s.d. & mean & s.d. \\
\hline $1973 \ldots$ & 46 & 0.76 & 3.9 & 67 & 25.8 & 20 & 20.5 \\
\hline 1974 & 59 & 0.68 & 4.1 & 81 & 19.8 & 12 & 14.1 \\
\hline 1975 & 58 & 0.56 & 4.1 & 90 & 9.3 & 6 & 8.6 \\
\hline 1976. & 60 & 0.55 & 4.7 & 93 & 4.6 & 4 & 4.3 \\
\hline $1977 \ldots$ & 60 & 0.43 & 5.0 & 94 & 3.9 & 3 & 3.5 \\
\hline $1978 \ldots$ & 58 & 0.48 & 4.2 & 88 & 14.0 & 8 & 13.1 \\
\hline 1979. & 59 & 0.48 & 3.9 & 93 & 6.9 & 5 & 6.8 \\
\hline
\end{tabular}

The selection results in the Ll-line are self-evident. A more variable result was obtained in the HI-line. Real progress in increasing the percentage of abnormal sperm cells was not be achieved.

The qualifications of the cocks examined per line and per generation, presented in figures 1 and 2, confirm these findings. 
TABLE 2

Mean sperm characteristics of HI-males; means per generation

\begin{tabular}{cccccccc}
\hline Year & $n$ & $\begin{array}{c}\text { Mean vol. } \\
\mathrm{ml}\end{array}$ & $\begin{array}{c}\text { Mean conc. } \\
\times 10^{9} / \mathrm{ml}\end{array}$ & $\begin{array}{c}\text { p. } 100 \text { norm. spermatozoa } \\
\text { mean }\end{array}$ & \multicolumn{2}{c}{$\begin{array}{c}\text { p. } 100 \text { abn. spermatozoa } \\
\text { mean }\end{array}$} & $\begin{array}{c}\text { s.d. } \\
\text { s.d. }\end{array}$ \\
\hline $1973 \ldots$ & 54 & 0.70 & 3.7 & 63 & 29.1 & 25 & 24.7 \\
1974. & 61 & 0.61 & 3.4 & 58 & 26.6 & 32 & 22.3 \\
$1975 \ldots$ & 61 & 0.46 & 3.9 & 68 & 25.9 & 25 & 22.3 \\
1976. & 57 & 0.52 & 4.4 & 65 & 27.0 & 25 & 22.3 \\
1977. & 60 & 0.47 & 4.4 & 63 & 24.4 & 28 & 20.6 \\
$1978 .$. & 59 & 0.56 & 4.0 & 60 & 25.8 & 33 & 22.5 \\
$1979 \ldots$ & 59 & 0.41 & 3.0 & 62 & 24.5 & 31 & 22.0 \\
\hline
\end{tabular}

TABLE 3

Mean sperm characteristics of males (control) ; means per generation

\begin{tabular}{cccccccc}
\hline Year & $n$ & $\begin{array}{c}\text { Mean vol. } \\
\mathrm{ml}\end{array}$ & $\begin{array}{c}\text { Mean conc. } \\
\times 109 / \mathrm{ml}\end{array}$ & $\begin{array}{c}\text { p. } 100 \text { norm. spermatozoa } \\
\text { mean }\end{array}$ & \multicolumn{2}{c}{$\begin{array}{c}\text { p. } 100 \text { abn. spermatozoa } \\
\text { mean }\end{array}$} & s.d. \\
\hline $1973 \ldots$ & 60 & 0.60 & 3.3 & 69 & n.a. & 21 & n.a. \\
$1974 \ldots$ & 40 & 0.61 & 3.6 & 81 & n.a. & 15 & n.a. \\
$1975 \ldots$ & 65 & 0.50 & 3.5 & 76 & n.a. & 17 & n.a. \\
\hline
\end{tabular}

n.a. : not available.

TABLE 4

Fertility and hatchability of the LI-line

\begin{tabular}{ccccc}
\hline Year & Eggs set & $\begin{array}{c}\text { P. } 100 \text { fert. } \\
\text { F./T.E. }\end{array}$ & $\begin{array}{c}\text { P. } 100 \text { hatch. } \\
\text { H./T.E. }\end{array}$ & $\begin{array}{c}\text { P. } 100 \text { hatch. } \\
\text { H./F.E. }\end{array}$ \\
\hline $1973 \ldots \ldots$ & 545 & 93 & 83 & 89 \\
$1974 \ldots \ldots$ & 824 & 97 & 76 & 79 \\
$1975 \ldots \ldots$ & 724 & 95 & 81 & 85 \\
$1976 \ldots \ldots$ & 294 & 91 & 57 & 63 \\
$1977 \ldots \ldots$ & 520 & 95 & 76 & 80 \\
$1978 \ldots \ldots$ & 526 & 98 & 78 & 80 \\
$1979 \ldots \ldots$ & 421 & 93 & 67 & 72 \\
\hline
\end{tabular}

TABLE 5

Ferfility and hatchability of the HI-line

\begin{tabular}{ccccc}
\hline Year & Eggs set & $\begin{array}{c}\text { P. } 100 \text { fert. } \\
\text { F./T.E. }\end{array}$ & $\begin{array}{c}\text { P. } 100 \text { hatch. } \\
\text { H./T.E. }\end{array}$ & $\begin{array}{c}\text { p. } 100 \text { hatch. } \\
\text { H./F.E. }\end{array}$ \\
\hline $1973 \ldots \ldots$ & 603 & 88 & 63 & 72 \\
$1974 \ldots \ldots$ & 758 & 81 & 64 & 79 \\
$1975 \ldots \ldots$ & 632 & 89 & 65 & 74 \\
$1976 \ldots \ldots$ & 372 & 73 & 48 & 66 \\
$1977 \ldots \ldots$ & 508 & 64 & 48 & 75 \\
$1978 \ldots \ldots$ & 587 & 88 & 64 & 72 \\
$1979 \ldots \ldots$ & 504 & 84 & 56 & 67 \\
\hline
\end{tabular}


TABLE 6

Fertility and hatchability of the control line

\begin{tabular}{ccccc}
\hline Year & Eggs set & $\begin{array}{c}\text { P. } 100 \text { fert. } \\
\text { F./T.E. }\end{array}$ & $\begin{array}{c}\text { P. } 100 \text { hatch. } \\
\text { H./T.E. }\end{array}$ & $\begin{array}{c}\text { P. } 100 \text { hatch. } \\
\text { H./F.E. }\end{array}$ \\
\hline $1973 \ldots \ldots$ & 848 & 90 & 73 & 81 \\
$1974 \ldots \ldots$ & 853 & 91 & 73 & 80 \\
$1975 \ldots \ldots$ & 860 & 95 & 78 & 82 \\
\hline
\end{tabular}

The data on fertility and hatchability are summarized in tables 4 and 5 . There appeared to be no significant difference in embryonic mortality between the lines.

Table 6 presents this data on three generations of the control line. Fertility and hatchability in the LI-line were consistently better than in the other lines.

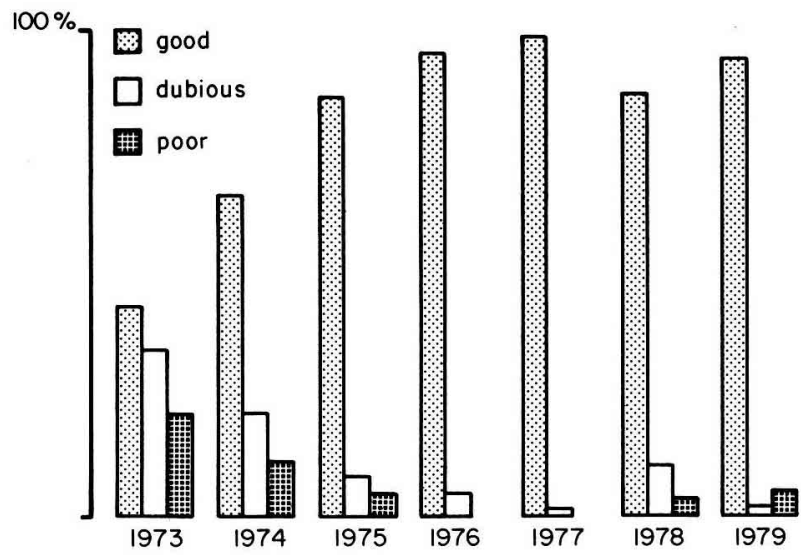

FIG. 1. - Classification of Ll-cocks in p. 100 of males examined per generation.

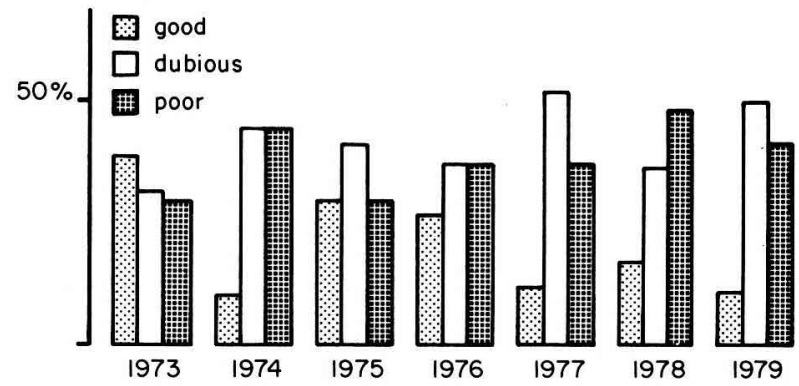

FIG. 2. - Classification of HI-cocks in p. 100 of males examined per $g$ eneration.

The mean bodyweights of the males and females at the age of 8 weeks, presented in figures 3 and 4 , show that selection on semen quality had no influence on 8-week bodyweight. 


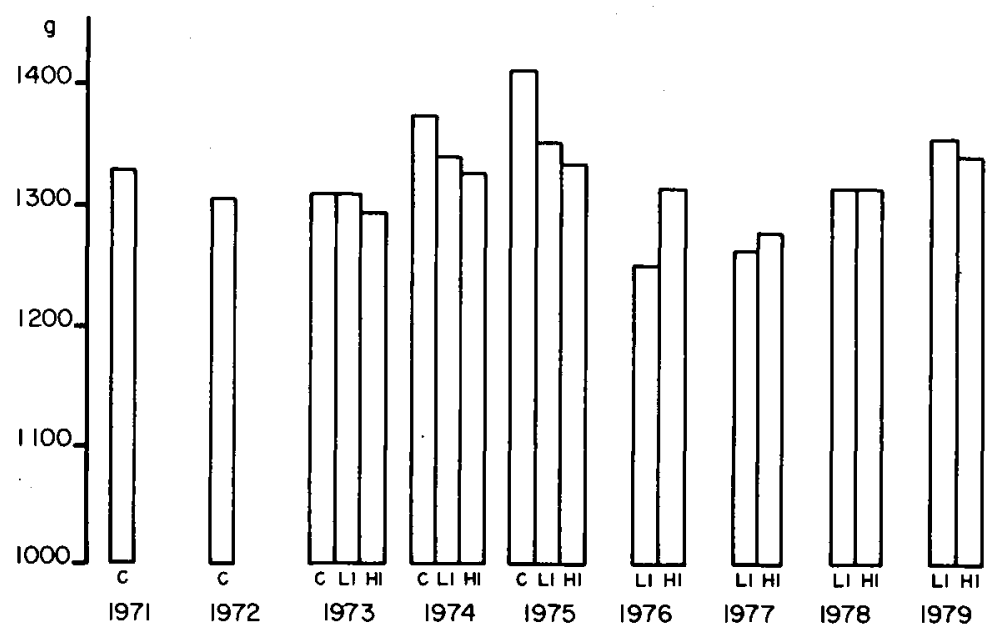

FIG. 3. - Mean body-weight at 8 weeks in the C(ontrol) line, LI- and HI-line males.

The realized selection differentials for the percentage of live and normal sperm cells and of abnormal sperm cells for both lines are given in figure 5 . This figure demonstrates clearly the success obtained in establishing a LI-line and, in contrast, the failure to found an HI-line.

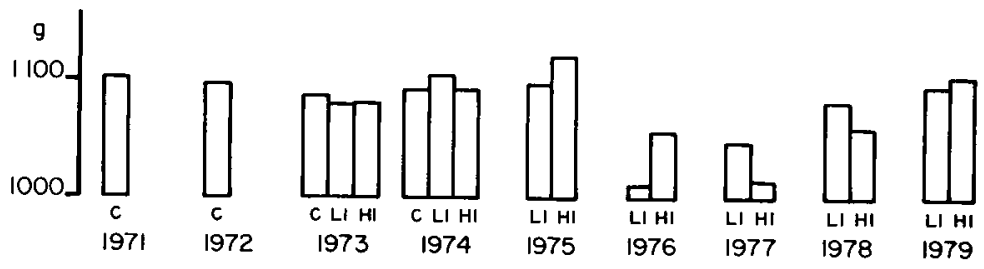

FIG. 4. - Mean body-weight at 8 weeks in the $C$ (ontrol) line, LI- and HI-line females.

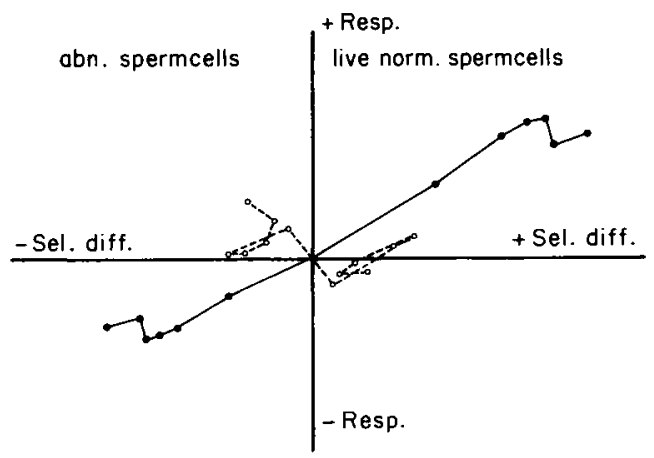

FIG. 5. - Realized selection differentials for p. 100 live and normal spermatozoa and p. 100 abnormal spermatozoa in Ll-line $(-\rightarrow)$ and HI-line (---o--). 


\section{Discussion.}

Many reports in the liferature concern semen quality and fertility (Parker and McKnegie, 1942 ; Cooper and Rowell, 1948 ; McDaniel and Craig, 1962 ; Soller et al., 1965). Others (Sampson and Warren, 1939 ; Saeki, 1961 ; Saeki and Brown, 1962) have reported the relation between the number of morphologically abnormal spermatozoa and fertility.

Vital staining of sperm smears is used to determine the number or percentage of abnormal sperm cells and to differentiate between live and dead spermatozoa (Edens ef al., 1973). A simple method was used which proved to be reliable in a large number of tests at the Institute. Staining with anilin blue or cottonblue and eosin was preferred on account of better contrast and more distinct cell boundaries (Shaffer and Almquist, 1948). Special care was taken to use the proper stains and a standardized preparation procedure, and the smears were prepared immediately after semen collection.

Classification of the different abnormalities observed produced many problems and so it was decided to use the total percentage of morphologically abnormal spermatozoa as the selection parameter. Other sperm traits can also be used to determine sperm quality.

Motility of the spermatozoa is frequently used on account of its correlation with fertility (McDaniel and Craig, 1962; Wall and Boone, 1973) ; there is a relation between motility and membrane damage of the sperm cell (Gibbons, 1973). A reliable and objective measurement, however, is difficult to realize since many factors interfere. Every semen sample in this experiment has been observed with a phase contrast microscope at $40^{\circ} \mathrm{C}$.

Estimations of motility were made immediately after collection. Semen with an excellent motility always had a low incidence of abnormal sperm cells. There were however numerous sperm samples with moderate motility and a low incidence of abnormalities.

A white colour and high viscosity are often considered as reliable traits of good quality. The ejaculates of many cocks meeting these qualifications, however, had a high incidence of abnormal sperm cells. The origin of morphological abnormalities is probably manifold. It is inconceivable that they are only the direct or indirect result of genetic factors, and this may be one of the reasons why the selection of the Hl-line had no response. Furthermore, a high selection pressure cannot be used to obtained enough offspring in this line.

In this respect it that the absence of response to the selection of the HI-line is an example of what Lerner calls « approaching the physiological limit » (Lerner, 1961).

Heavy selection pressure could be applied in the LI-line. After three generations, a remarkable response was already obtained. The breeding period in both lines took place at the end of the productive period of the hens and this may have affected the results.

Breeding cocks of both lines were used, however, in many other experiments together with WL-hens in full production. The results of the inseminations in those crosses showed the same differences in fertility.

There are many reports on the influence of selection for growth on semen traits (Marini and Goodman, 1969 ; Soller and Snapir, 1966 ; Soller and Rappaport, 1971 ; 
Edens et al., 1973 ; Van Krey and Siegel, 1974 ; Cheng and Goodman, 1976). Negative genetic correlations between bodyweight at 8 weeks and semen quality parameters are reported. The selection on sperm quality in this experiment did not bring about a significant difference in the 8-week bodyweight of either the males or the females in either line. The main aim of this experiment was to obtain useful information on the possibility and consequences of selection on sperm quality to improve the efficiency of artificial insemination without undesirable side-effects.

This purpose has been achieved. It seems reasonable to assume that screening for the sperm quality of cocks, employed for artificial insemination in the breeding stock of meat birds, can be performed without fear of losing important genetic properties.

Workshop on «Avian male reproduction » Nouzilly, France, June 1980.

Résumé. Des coqs White Plymouth Rock de l'Institut Sperderholt ont fait l'objet d'une sélection divergente à 26 semaines d'âge d'après la qualité de leur sperme, en utilisant principalement le taux de spermatozoïdes anormaux sur frottis, après coloration vitale. La réponse à cette sélection est apparue évidente dans la lignée à faible incidence de spermatozoïdes anormaux alors qu'elle est variable dans la lignée à haute incidence. On a pu montrer ainsi un effet indirect de la sélection faite sur le poids à 8 semaines d'âge.

\section{References}

CHENG K. M., GOODMAN B. L., 1976. The influence of divergent growth selection on semen traits, fertility and hatchability. Poult. Sci., 55, 457-459.

COOPER D.M., ROWELL J. G., 1958. Relations between fertility, embryonic survival and some semen characteristics in the chicken. Poult. Sci., 37, 699-707.

EDENS F. W., VAN KREY H. P., SIEGEL P. B., 1973. Selection for bodyweight at eight weeks of age. Poult. Sci., 52, 2287-2289.

GIBBONS I. R., 1973. Mechanisms of flagellar motility in Afzelius B. A., The functional anatomy of the spermatozoon. Proc. 2nd int. Symp. Wenner-Gren Center, Stockholm, Pergamon Press Oxford, New York, Toronto, Sidney.

KREY van H. P., SIEGEL P. B., 1974. Selection for bodyweight at eight weeks of age. Poult. Sci., 53, 741745.

LERNER 1. M., 1961. Response to selection pressure, 109-152. In LERNER J. M., The genefic basis of selection. John Wiley and Sons Inc., New York, London.

MCDANIEL G. R., CRAIG J. V., 1962. Predicting male fertilizing capacity in high and low fertility strains of chickens. Poult. Sci., 41, 866-869.

MARINI P. J., GOODMAN B. L., 1969. Semen characteristics as influenced by selection for divergent growth rate in chickens. Poult. Sci., 48, 859-865.

PARKER J. E., 1961. Observations on the low fertility problems in Cornish cockerels. Poult. Sci., 40, 1214-1219.

PARKER J. E., McKNEGIE F. F., 1942. Res. Bull. Missouri agric. exp. Station, 347, 40.

SAEKI Y., 1961. Crooked-necked spermatozoa in relation to low fertility in the artificial insemination of fowl. Poult. Sci., 39, 1354-1361.

SAEKI Y., BROWN K. 1., 1962. Effect of abnormal spermatozoa on fertility and hatchability in the turkey. Poult. Sci., 41, 1096-1100.

SAMPSON F. R., WARREN D. C., 1939. Density of suspension and morphology of sperm in relation to fertility in the fowl. Poult. Sci., 18, 301-307.

SHAFFER H. E., ALMQUIST J. O., 1948. Vital staining of bovine spermatozoa with an eosin-anilinblue 
staining mixture. J. Dairy Sci., 31, 677.

SOLLER M. BORNSTEIN S., SCHINDLER H., 1965. Semen characteristics, failure of insemination and fertility of Cornish and White Rock males. Poult. Sci., 44, 424-432.

SOLLER M., SNAPIR N., SCHINDLER H., 1966. Heritability of semen quality, concentration and motility in White Rock roosters and their genetic correlation with rate of gain. Poult. Sci., 44, 1527-1529.

SOLLER M., RAPPAPORT S., 1971. Correlation between growth rate and male fertility and some observations on selection for male fertility in broiler stocks. Poult. Sci., 50, 248-256.

WALL K. A., BOONE M. A., 1973. Objective measurement of sperm motility. Poult. Sci., 52, 657-660. 